\title{
Um ambiente de interação Universidade/Empresa: experiências com a prática do desenvolvimento de produtos em uma fábrica integrada modelo
}

\author{
Henrique Rozenfeld, $D r$. \\ Sergio Luis da Silva, $D r$. \\ Daniel Capaldo Amaral, $D r$. \\ Eduardo de Senzi Zancul, M.Sc. \\ Núcleo de Manufatura Avançada - NUMA - Universidade de São Paulo - USP
}

\begin{abstract}
A vantagem competitiva das empresas da maioria dos setores produtivos relaciona-se cada vez mais a sua capacidade de desenvolver novos produtos. Neste artigo apresenta-se um tipo de interação Universidade/Empresa que busca auxiliar empresas do setor metal-mecânico a incrementar esta capacidade. Trata-se de uma experiência que ocorre em um ambiente próximo do real, denominado de FIM (Fábrica Integrada Modelo), e que é usada para testar novas soluções tecnológicas e gerenciais de empresas, bem como treinar pessoas nos conhecimentos explícitos e tácitos relacionados à execução do processo de desenvolvimento de produtos. Baseia-se em uma forma atual de se visualizar o desenvolvimento de produtos como um processo de negócios, comumente chamado de engenharia simultânea, e representado através de um modelo de referência. A concepção teórica utilizada para desenvolver este ambiente, as atividades realizadas, e os resultados atingidos são aqui apresentados.
\end{abstract}

Palavras-chave: engenharia simultânea; desenvolvimento de produtos; fábrica modelo.

The competitive advantage of the enterprises in most of productive sectors has been related more and more with a capacity to develop new products. In this article a kind of interaction University/Enterprise is presented with the objective of supporting enterprises in metal-mechanical sector to increase this capacity. It refers to an experience that has taken place in an environment next to the real, named as FIM (Integrated Model Factory), used to test new technical and management solutions for enterprises and training people in explicit and tacit knowledge related to the execution of product development process. All of these are based on an actual way to visualize the product development as a business process, normally named Concurrent Engineering, and represented by a reference model. The theoretical concepts used to develop this environment, the activities done, and the results obtained, are presented here.

Keywords: concurrent engineering; product development; model factory.

\section{Introdução}

Em um cenário de atuação cada vez mais em nível global, a vantagem competitiva das empresas está diretamente conectada com sua capacidade de introduzir novos produtos, simultaneamente obtendo períodos de tempo, qualidade e custos compatíveis com o que é exigido pelo mercado.

O processo de desenvolvimento de produtos é um teste crucial para se verificar em como está a integração das habilidades funcionais de uma organização e quão bem usados são seus conhecimentos. Sendo assim, as pessoas da área de desenvolvimento de produtos devem estar bem preparadas em termos dos detalhes deste processo, da integração funcional e dos conhecimentos envolvidos, todos estes aspectos norteados pela forma contemporânea de se realizar o desenvolvimento de produtos, através da engenharia simultânea.
Entretanto, muitas empresas têm focalizado somente os aspectos organizacionais da engenharia simultânea, apenas agrupando pessoas que antes estavam em departamentos separados. Outras têm investido esforços na integração de sistemas computacionais de suporte ao projeto (por exemplo, sistemas CAD/CAE/ CAPP) para que estes compartilhem um mesmo modelo de produto. Em síntese, devido ao foco em somente um ou outro aspecto específico, o potencial pleno da filosofia de projeto dada pela engenharia simultânea não tem sido explorado.

Para se obter melhores benefícios desta filosofia é necessário se considerar, ao mesmo tempo, ou pelo menos ter consciência, de todas as dimensões envolvidas no processo de negócio, no caso, o desenvolvimento do produto.

Neste sentido, para suprir a necessidade de um lugar onde as pessoas de empresas possam ver e interagir 
com um modelo implementado e completo de engenharia simultânea, foi criada uma Fábrica Integrada Modelo (FIM), um ambiente próximo do real onde o processo de desenvolvimento de produtos é simulado de diversas formas. Este ambiente tem sido usado como uma plataforma para o teste de novas soluções para o processo de desenvolvimento de produtos e também para o ensino dos conhecimentos tácitos e explícitos existentes neste processo, tudo entendido em um contexto de uma visão integrada. Estas soluções (conceitos, filosofias, técnicas, métodos, ferramentas e equipamentos) podem tanto ser soluções comerciais adaptadas a este ambiente, como também resultados de pesquisa, quando soluções comerciais não existem ou não estão disponíveis. $\mathrm{O}$ ambiente envolve então uma prática integrada de ensino e pesquisa do desenvolvimento de produtos, voltado a um setor específico, tipificando uma nítida interação entre universidade e empresa, que ocorre em vários níveis.

O objetivo deste artigo é descrever esta experiência de interação entre universidade e empresa que ocorre na Fábrica Integrada Modelo visando o incremento da capacidade de desenvolvimento de novos produtos das empresas. Inicia-se por apresentar a concepção teórica que forma a base necessária para apoiar a construção deste ambiente, e das atividades que aí se desenvolvem. Em seguida, as atividades realizadas em termos de prática do desenvolvimento de produtos na FIM são descritas, notadamente o ensino, a pesquisa, e a assessoria, que ocorrem de forma totalmente entrelaçadas e interdependentes, nitidamente exibindo a forte interação entre universidade e empresa desta experiência. Destaca-se em um tópico a questão específica do treinamento de pessoal de empresas dentro das instalações desta FIM, nos conhecimentos explícitos e tácitos relacionados à execução do processo de desenvolvimento de produtos, que é uma das formas de se aplicar e testar todo este esforço de ensino, pesquisa e assessoria. Por fim, uma discussão sobre resultados atingidos e suas implicações são expostos, tanto do ponto de vista da atuação da FIM quanto da melhora do entendimento acadêmico sobre o desenvolvimento de produtos, como também sobre seu impacto sobre a interação universidade/empresa.

\section{0 desenvolvimento de produtos entendido como um processo em uma abordagem de engenharia simultânea}

Conforme salienta Clausing (1993), antes do meio do século, eram os generalistas com o conhecimento sobre todo o produto que conduziam a realização do desenvolvimento. Esta abordagem foi possível devido à maior simplicidade tecnológica dos produtos daquela época.
Com o advento do progresso tecnológico e o crescimento da complexidade do produto, esta abordagem tornou-se inviável. Em um contexto de produção em massa, a realização do desenvolvimento de produtos passou a ser feita em uma forma funcional, com funções trabalhando isoladamente em diferentes partes, fases ou atividades do desenvolvimento do produto. Passa então a ser necessária a presença de especialistas em cada um destes segmentos, tendo como contrapartida o fato de que estas pessoas passam a ter uma visão cada vez menos completa de todo o desenvolvimento de produtos.

Estes atributos profissionais resultaram em muitos problemas e limitações para o desenvolvimento de produtos: dificuldades para projetar o produto como um todo de forma simples, perda de atenção para com a qualidade final do produto, excessivos tempos de desenvolvimento, perda de integração entre as fases de projeto e produção, perda de foco no cliente, pouco envolvimento dos fornecedores no desenvolvimento de produto etc. Uma das principais causas de todas estas limitações é o fato de que as pessoas envolvidas no projeto do produto contribuem somente como especialistas em uma dada fase do processo. Estas limitações eram toleradas pelo mercado, pensando em termos gerais, pelo fato de a demanda ser maior que a oferta, aceitando-se sem maiores restrições as deficiências advindas deste produto manufaturado.

Esta tolerância tem mudado nos anos recentes, de demandas saturadas e maiores possibilidades de escolhas de produtos pelo consumidor, ampliandose esta escolha para um mercado global. Neste cenário, restaurar uma visão de processos para a realização do desenvolvimento de produtos tem sido cada vez mais relevante. Em um contexto de empresas enxutas e ágeis, o desenvolvimento de produtos vem cada vez mais sendo visto como um processo que precisa de mais comunicações e integração das pessoas das diferentes áreas funcionais envolvidas. Outra importante mudança é que o foco dado ao cliente final por esta visão de processos é mais relevante que o dado pela visão funcional. Uma abordagem superior que ganha evidência com esta visão de processos é a formação de times de desenvolvimento de produtos com membros multifuncionais, fazendo-se assim uma boa combinação de conhecimentos tanto em termos de profundidade como de escopo, e melhorando-se a comunicação entre os envolvidos (CLAUSING, 1993).

\subsection{Filosofia da Engenharia Simultânea}

Esta visão de processos, em algumas empresas denominada de Filosofia da Engenharia Simultânea 
quando referindo-se ao processo de desenvolvimento de produtos envolvido em um contexto holístico de empresa, tem resultado em uma considerável redução de tempos de desenvolvimento, melhoria dos parâmetros de qualidade e maior produtividade das atividades relacionadas. Nesta abordagem, a Engenharia Simultânea é definida como uma filosofia utilizada ao longo do processo de desenvolvimento de produtos, que deve ser conduzida por um time multifuncional, realizando as atividades do projeto de forma simultânea e tomando decisões baseadas nos requisitos e experiências de todas as áreas envolvidas.

Ter uma visão holística na empresa significa ter todos os elementos da empresa sintetizados em uma única imagem na mente de cada pessoa que nela trabalha. Esta visão tem diferentes dimensões e graus de abstração. As dimensões são suas estratégias, informações, atividades de negócio, recursos e organização, bem como suas inter-relações (Figura 1).

Muitos gerentes vêm de áreas específicas e trazem consigo uma visão distorcida do todo, focalizando apenas sua dimensão específica na tomada de decisões. Entretanto, adquirindo-se uma visão holística assegurase decisões mais seguras, pois não somente uma dimensão é levada em conta mas sim as consequiências em todas as outras dimensões existentes na empresa. Se
Um processo de negócios consiste de um grupo de atividades que manipula e é ligado por informações. Estas atividades usam os recursos e a organização da empresa. O processo de negócios forma uma unidade coesa e deve ser focalizado em um negócio que por sua vez foca em um cliente/mercado específico, com fornecedores definidos (ROZENFELD, 1996).

A competição crescente, os novos requisitos do cliente e as tecnologias de informação mais flexíveis fazem necessário a identificação dos processos de negócio existentes na empresa e que toda a organização pense desta forma (GARVIN, 1995). O mapa dos processos de negócio existentes na empresa é essencial como uma referência para discussões, para auxiliar na formação sistemática de uma visão holística na empresa. O modelo de referência é a ferramenta usada para representar este processo de negócio.

Muitas dificuldades aparecem durante o processo de implementação da engenharia simultânea baseada na abordagem apresentada aqui. Uma primeira dificuldade envolve a criação de um modelo de referência para o processo de desenvolvimento de produtos, que deve incluir os aprendizados das melhores práticas e refletir os requisitos da empresa e de seus produtos. A manutenção deste modelo de referência é um elemento-chave no

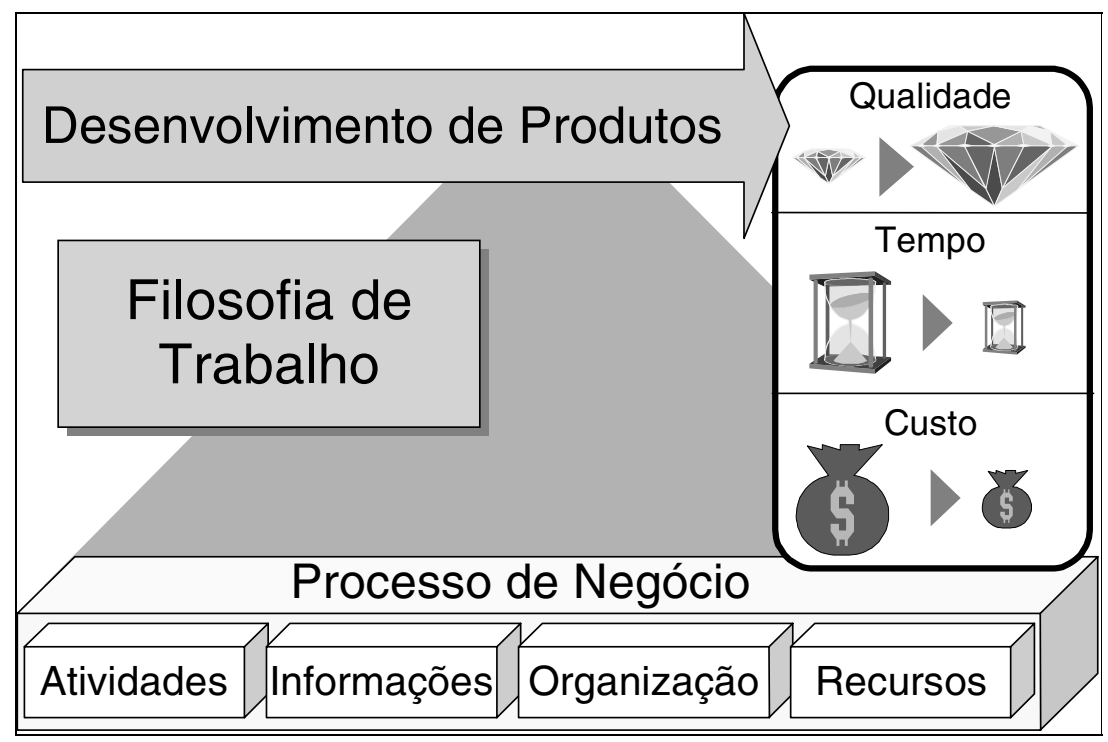

Figura 1 - Definição da Engenharia Simultânea

esta visão holística for formalizada, problemas específicos podem ser discutidos sem perder a compreensão do todo, e os conhecimentos envolvidos podem ser melhor equalizados entre os participantes da discussão.

Entretanto, a visão holística é uma imagem abstrata, em que todas as áreas da empresa são sintetizadas na mente das pessoas. Sendo assim, a melhor forma de representar formalmente esta visão holística é vendo a empresa como uma coleção de processos de negócio. melhoramento contínuo da forma de se projetar produtos na empresa.

Um outro problema é a seleção e integração de uma larga faixa de ferramentas computacionais desenvolvidas para suportar as aplicações da engenharia simultânea. Estas ferramentas são difíceis de selecionar porque cada fabricante de software oferece sua solução como sendo suficiente para atender todas 
as aplicações. Integrar estas ferramentas é também difícil devido às suas funcionalidades, ora redundantes, ora não-complementares e que normalmente têm diferentes modelos de dados e não apresentam nenhuma padronização.

Uma integração conceitual de técnicas e métodos selecionados para suportar a Engenharia Simultânea é também necessária. Por exemplo, nas atividades da técnica de FMEA (Failure Mode and Effect Analysis) parte da entrada dos dados para sua realização (entrada do FMEA) é também utilizada para a montagem da macro operação do plano de processos (outra técnica) de fabricação e/ou montagem do produto. Mais do que isso, os controles do processo de fabricação e/ou montagem do produto e as ações recomendadas (resultados do FMEA) são usadas, respectivamente, no plano de controle e no teste de validação da produção. Sendo assim, havendo uma integração entre as etapas destas técnicas e métodos, a redundância na coleta e alimentação de dados de um documento para outro, bem como a falta de informação, podem ser eliminadas.

Finalmente, é fundamental para o sucesso da engenharia simultânea a melhora das habilidades das pessoas. Os membros dos times devem ter uma visão holística do processo de negócios do desenvolvimento de produtos e dos conhecimentos envolvidos. Entretanto, há o problema já mencionado de que muitas pessoas na empresa têm apenas habilidades parciais. Há os especialistas que têm uma visão muito concentrada em somente uma área técnica e pouca visão do todo e dos aspectos administrativos do processo de desenvolvimeno de produtos, e há os generalistas, ou os gerentes pensando-se de forma mais pragmática, que podem ser bem versados nestes aspectos administrativos mas muitas vezes possuem pouca habilidade para transitar entre os diversos aspectos tecnológicos do processo de desenvolvimento de produtos.

Considerando estas dificuldades, há muitos requisitos envolvidos na criação de um ambiente de engenharia simultânea, tanto pensando-se em um ambiente real na empresa como principalmente em um ambiente para o teste de soluções e o ensino de pessoas (que é a experiência da FIM apresentada neste artigo):

- este ambiente deve ser criado a partir de um modelo de referência para o processo de negócios do desenvolvimento de produtos. O modelo de referência deve conter tantas alternativas quanto forem possíveis e sua configuração deve ser flexível para que se possa representar facilmente modificações do ambiente;

- $\quad$ este ambiente deve ser suficientemente flexível para que seja facilmente modificado e assimile novos conceitos e tecnologias de acordo com mudanças que ocorram no modelo de referência;

- este ambiente deve fazer grande uso e integração de soluções tecnológicas comerciais (disponível para aquisição no mercado), o que o aproxima mais dos recursos disponíveis para uma empresa para que esta proceda uma aplicação real da Engenharia Simultânea;

- além destas soluções comerciais, este ambiente deve também ser capaz de fazer uso de novas soluções tecnológicas advindas de pesquisas acadêmicas recentes, e em ambos os casos espera-se uma ampla capacidade de testes e identificação de limitações e sobreposições de cada solução;

- este ambiente deve ser propício para o treinamento e a reciclagem de pessoas envolvidas com o processo de desenvolvimento de produtos, seja em aspectos ligados à Engenharia Simultânea, seja em ferramentas computacionais e/ou técnicas e métodos que suportam este processo;

- por fim, este ambiente deve exibir os principais conhecimentos envolvidos em um processo de desenvolvimento de produtos e mostrar como estes conhecimentos podem ser enriquecidos através de seu manuseio e organização sistemática.

\subsection{O trabalho com os conhecimentos envolvidos no desenvolvimento de produtos sob a filosofia da Engenharia Simultânea}

Há nos dias atuais crescente quantidade de informação e conhecimento, constantemente atualizados, sobre mercados, tecnologias e consumidores, que precisam ser obtidos e incorporados aos projetos de produtos. Há também uma grande quantidade de informações e conhecimentos advindos do crescente número de projetos realizados pela empresa a fim de se atender à diversificação do mercado. A adoção da filosofia da Engenharia Simultânea no processo de desenvolvimento de produtos, suportada pela tecnologia da informação, técnicas e métodos de projeto, e pelo trabalho de times multifuncionais, tem produzido não somente melhores produtos mas também uma crescente necessidade de se utilizar uma ampla gama de conhecimentos relacionados à ferramentas, sistemas, metodologias, soluções etc., em muitos casos desenvolvidos por profissionais e empresas de diferentes áreas.

Neste contexto, o trabalho com o conhecimento no processo de desenvolvimento de produtos tem adquirido importância crescente e requer cuidados especiais das pessoas envolvidas, de acordo com os mais 
respeitados autores deste tema (NONAKA e TAKEUCHI, 1995; DAVENPORT e PRUSAK, 1998; LEONARD, 1995).

Mesmo os autores que apresentam contribuições valiosas para os estudos ligados ao desenvolvimento de produtos (CLARK e FUJIMOTO, 1991; CLARKe WHEELWRIGHT, 1992; CUSUMANO e NOBEOKA, 1998; PRASAD, 1997) também consideram importante a relação do conhecimento com esta atividade, por exemplo, no foco que tem dado à inovação (conhecimento) criada por times trabalhando simultaneamente conduzidos por um líder de projeto, ou na sistematização do conhecimento indiretamente obtido pela modelagem do processo de desenvolvimento de produtos, ou ainda na aplicação de sistemas baseados em inteligência artificial/base de dados utilizadas como suporte ao projeto.

Considerando então a importância de se visualizar o desenvolvimento de produtos como um processo integrado com intrínsecas ligações com os conhecimentos envolvidos, e considerando-se também que estes conhecimentos não são recursos estáticos mas sim que se enriquecem pelo dinamismo com que são manuseados e trabalhados, principalmente em atividades de ensino e simulação como as que são realizadas com o desenvolvimento de produtos no ambiente da FIM, faz-se aqui algumas considerações sobre alguns aspectos fundamentais ligados ao trabalho com o conhecimento, iniciando-se pela sua definição e pelos seus dois formatos básicos.

Há muitas definições sobre conhecimento, todas convergindo para a idéia de que trata-se de informação combinada com experiência, contexto, interpretação e reflexão. Há também um amplo consenso de que o conhecimento existe no formato tácito (habilidades inerentes a uma pessoa, difícil de ser formalizado ou explicado a outra pessoa) e no formato explícito (publicações em geral, textos em formato eletrônico na web ou em bases de dados), sendo que os autores mais relevantes neste tema (NONAKA e TAKEUCHI, 1995; DAVENPORT e PRUSAK, 1998; LEONARD, 1995) consideram que um trabalho efetivo com o conhecimento somente é possível em um ambiente onde possa ocorrer a contínua conversão dos conhecimentos entre estes dois tipos de formatos.

Seguindo esta preocupação, muitos autores com um foco inicial somente voltado aos recursos da tecnologia da informação para se trabalhar com os conhecimentos têm reconhecido a importância de considerar os fatores humanos em seus métodos, técnicas e ferramentas. Estes autores lembram que a essência da criação do conhecimento ocorre quando pessoas podem encontrar-se e trocar experiências com outras pessoas que têm ou trabalharam com algum tipo de conhecimento, e a tecnologia da informação tem sua importância efetiva em construir um suporte para fazer com que isso ocorra (PROKESCH, 1997; NICOLETTI, 1998; JUNNARKAR, 1997).

Este esforço de integração para a gestão do conhecimento entre a tecnologia da informação e o fator humano é visível em inúmeros e abrangentes trabalhos que procuram integrar, do lado da tecnologia, a idéia de navegar por vários conhecimentos relacionando-os através de hipertexto, com recursos multimídia, usando intranet ou internet, e do lado humano, a idéia de contextualizar a criação e/ou o trabalho com o conhecimento pelo registro da ocorrência em que isso ocorreu através do uso de casos, lessons learned, best practices, bad practices, learning history, scripts, redes semânticas, frames, mapas, cenários (BIRCHALL e SMITH, 1998; HEIJST et al., 1997; ABECKER et al., 1998; MAURER, 1998; SCOTT, 1998).

A dinâmica de consultar esta memória organizacional com as facilidades e interatividade permitida pela tecnologia proposta, fazer uma análise do conteúdo consultado, procurar as pessoas ou conhecimentos registrados, e em seguida tomar decisões com base nos conhecimentos obtidos e registrar estas decisões incrementando assim a memória organizacional, forma um perfeito e contínuo ciclo de conversão de conhecimentos explícitos/tácitos/explícitos. Como críticas ou limitações associadas a estas propostas, há o perigo do apego ao passado se esta memória acumulada for pensada como um repositório de soluções prontas e não com a visão de um repositório de idéias a serem adaptadas para criar soluções e oportunidades novas para problemas futuros. Há também o trabalho demorado e disciplinado que deve ser realizado continuamente para constituir esta memória organizacional (TEECE, 1998).

Procurando enfatizar a importância da espiral de conversão do conhecimento tácito/explícito/tácito, Nonaka e Takeuchi (1995) propõem três características-chave para a criação do conhecimento na empresa, particularmente pensando no processo de desenvolvimento de produtos:

- depositar grande confiança na linguagem figurada e no simbolismo (metáfora e analogia) que é uma forma eficaz de socialização e externalização do conhecimento tácito, ou seja, para a tentativa de transmissão das experiências e habilidades pessoais de uma pessoa para outros;

- deve ser incentivado que um indivíduo compartilhe seus conhecimentos com os outros, o que mostra o papel central desempenhado pelas equipes e times e por uma clara cultura de 
valorização do espírito crítico e das diferentes maneiras pessoais de se ver e de fazer as diversas atividades em um trabalho de desenvolvimento de produtos;

- e por fim, incentivar-se também uma certa ambigüidade e redundância, que pode ser um estímulo a um novo senso de direção, uma fonte de novas idéias e de formas diferentes de se pensar, e a um diálogo e comunicação freqüentes.

Estes autores enfatizam a importância de uma espiral de conversão do conhecimento entre os formatos tácito e explícito, composta de quatro modos: socialização (quando o conhecimento tácito de um indivíduo passa para o outro, essencialmente ligado aos aspectos do trabalho em grupo); externalização (quando o conhecimento tácito de um indivíduo passa para o formato explícito e é disponibilizado, a metáfora e a analogia assumem grande importância aqui); combinação (quando diversos conhecimentos explícitos são agrupados dando origem a outros conhecimentos explícitos, bastante ligado às teorias do processamento da informação); e internalização (quando estes conhecimentos explícitos agrupados são incorporados pelo indivíduo e passam a fazer parte de seu conhecimento tácito, bastante abordado pelas teorias ligadas à aprendizagem organizacional).

Complementando esta abordagem de Nonaka e Takeuchi (1995), o trabalho de Leonard (1995) propõe que o trabalho com o conhecimento na empresa está relacionado ao desenvolvimento de suas competências/capacidades essênciais (core competence/core capabilities), que ocorre pela realização de quatro atividades inter-relacionadas (tendo como uma forte preocupação a inovação de produtos e processos na empresa):

- a primeira atividade é o compartilhamento da tarefa de solução de problemas, que preocupa-se em reunir visões diferentes em uma atividade denominada creative abrasion, ou confrontação construtiva para a análise de problemas;

- a segunda atividade, implementação e integração da solução em desenvolvimento no ambiente em que será utilizado, foca o grau e o tipo de envolvimento do cliente durante um projeto, adaptando-se tanto a tecnologia ao ambiente do usuário como o contrário, buscando-se explorar o potencial pleno da inovação;

- uma terceira atividade é a existência de um clima que tolere e mesmo encoraje a experimentação e a visualização de soluções através da criação de protótipos, desenvolvendo mecanismos para assegurar que a organização aprenda com estas atividades. A realização de uma análise crítica ao final do projeto ou de suas etapas (postproject audit) é a melhor forma de avaliar estas atividades e registrar os conhecimentos adquiridos;

- a quarta e talvez mais extensa atividade refere-se a importar e absorver conhecimentos externos à empresa. Pode-se pensar aqui desde a observação informal de alguma fonte, a realização de benchmarking, até a realização de alianças e jointventures. As empresas variam muito em sua habilidade de absorver novos conhecimentos tecnológicos e agrupá-los em novas capacidades.

Toda a concepção teórica apresentada neste item serve de base para a construção do ambiente para a prática do desenvolvimento de produtos em um contexto de Engenharia Simultânea, experiência esta que começa a ser relatada no próximo item.

\section{A prática do desenvolvimento de produtos um uma Fábrica Integrada Modelo}

Tradicionalmente, a maioria das instituições tem formado, nas áreas de projeto e manufatura, pessoas com alto grau de conhecimento especializado, sem possuir, no entanto, o perfil de gerenciamento, liderança e trabalho em equipe exigidos pela atual dinâmica competitiva e pelas mudanças que as novas tecnologias, principalmente a informática, causaram no ambiente e organização do trabalho. Além disso, muitas vezes estes especialistas galgam posições na hierarquia da empresa sem adquirir uma visão mais ampla do negócio, levando-os a assumir um enfoque que privilegia os aspectos relacionados com a área técnica da sua formação e experiência. É o caso típico de gerentes que crêem que a solução de todos os problemas da empresa está na tecnologia da informática, outros que apostam somente em mudanças organizacionais e outros em máquinas, equipamentos e novas tecnologias de fabricação. $\mathrm{Na}$ realidade, a solução de problemas em uma empresa passa por todos estes aspectos ao mesmo tempo, exigindo dos profissionais uma visão ampla que considere-os concomitantemente.

Isto é ainda mais evidente quando se trata do processo de desenvolvimento de produto, tradicionalmente tratado como projeto de produto. Este processo de negócio envolve atividades de diversas áreas funcionais afetando o trabalho de todos os seus membros, e, classicamente, é gerenciado e executado por pessoas com sólida formação tecnológica e de pouca visão sobre o funcionamento e necessidades das demais áreas da organização. Assim, uma grande barreira para a solução deste problema é a dificuldade de formar profissionais que possuam, além da formação técnica, 
uma visão abrangente e integrada da empresa, a qual denomina-se neste trabalho de visão holística.

Outro ponto importante sobre o ensino de projeto de produto é que cada vez mais se tem percebido a importância da prática de projeto como instrumento único no sentido de transmitir ao aluno uma base mais sólida de conhecimentos. Somente quando confrontados com situações reais é possível que iniciantes percebam a intrincada conexão entre os diversos elementos envolvidos nesta atividade (PUGH, 1996).

Neste sentido, propõe-se uma nova abordagem para a prática do processo de desenvolvimento de produto, em um ambiente denominado de Fábrica Integrada Modelo (FIM). Este espaço tem todos os elementos necessários para ser um ambiente bem próximo do real, tais como produtos, pessoas (personagens criados com uma posição profissional e responsabilidades), recursos de chão de fábrica (máquinas, robôs etc.), escritórios, entre outros. A FIM é então uma empresa próxima do real estruturada através de uma coleção de processos de negócios, tais como Marketing e Vendas, Desenvolvimento de Produtos e Serviços, Produção e Distribuição etc. De forma a usar estes processos de negócios como fontes de referência para um ambiente de manufatura real, ajudando-o a obter a visão holística, todos estes processos foram mapeados utilizando-se modelos de referência. Informações adicionais sobre a FIM podem ser encontrado em Bremer (1995).

A Figura 2 esquematiza as atividades necessárias para desenvolver este ambiente, conforme os requisitos expostos anteriormente (no item 2.1) para a criação de um ambiente de Engenharia Simultânea. Estas atividades serão discutidas em detalhes a seguir.

\subsection{Definição do modelo de referência (reference model)}

O modelo de referência para o desenvolvimento de produtos, que é construído através do uso de uma ferramenta de modelagem comercial, contém best practices do processo de desenvolvimento de produtos resultantes do aprendizado derivado de atividades de assessoria e benchmarking realizado por pesquisadores da FIM em empresas de classe mundial, e está em concordância com a QS 9000.

Este modelo de referência envolve todos os passos do desenvolvimento de produtos para um tipo de indústria (do setor metal-mecânico) e para um produto específico (um redutor modular). Este modelo segue desde a concepção de uma nova idéia até a validação do produto, incluindo o conceito e o projeto.

Na fase de Concepção, a idéia de um novo produto é criada, com suas especificações básicas e planejamento de tempos de desenvolvimento. Na próxima fase, do Conceito, as necessidades do consumidor são levantadas e a partir daí as especificações técnicas são determinadas, podendo-se começar as atividades seguintes, de desenhos de partes e de conjuntos, de planejamento de processo macro de fabricação e/ou montagem, de decisões quanto à fabricação interna ou compra em fornecedores, e de análises de investimentos.

$\mathrm{Na}$ fase de Projeto, os fornecedores são definidos, os componentes são especificados (formatos, dimensões, tolerâncias, materiais etc.) e os respectivos planos de processo de fabricação e/ou montagem (ferramentas, fixações, controles de qualidade etc.) são detalhados, entre outras coisas.

Na fase final do desenvolvimento, da Validação do Produto, os protótipos e os lotes pilotos são feitos para validar os respectivos projetos e processos de fabricação. Após a realização de todas as atividades destas fases mencionadas, a empresa pode começar a produção.

Nem todas as dimensões do processo de negócios do desenvolvimento de produtos (estratégias, informações, atividades, recursos e organização) são representadas neste modelo de referência, mas todos os conhecimentos levantados até agora, envolvidos com este processo, são mapeados e incorporados na forma de uma tipologia, e trabalhados em seus aspectos tácitos e explícitos, como será discutido adiante, através das práticas de desenvolvimento de produtos realizada neste ambiente. 


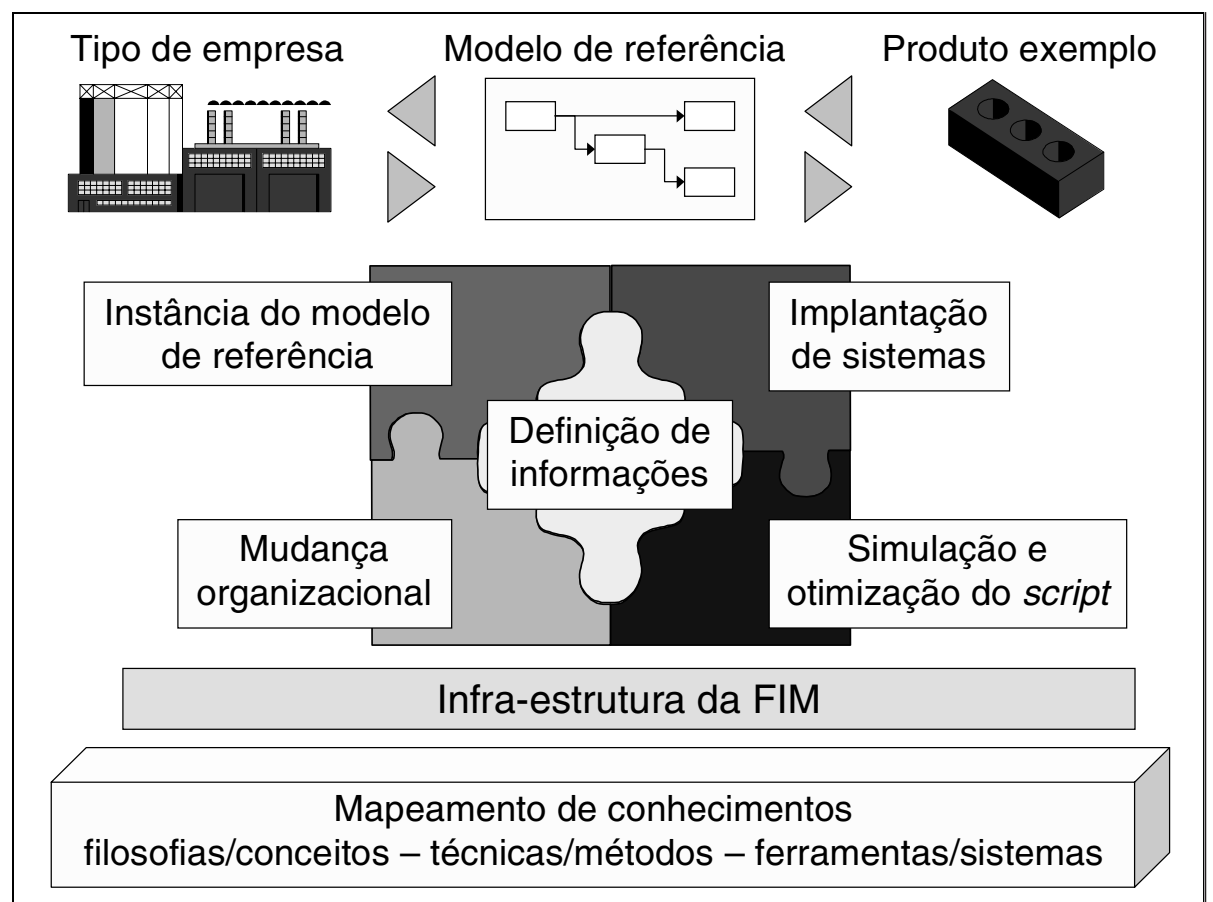

Figura 2 - Atividades para o desenvolvimento de um ambiente de Engenharia Simultânea

\subsection{Instâncias do modelo de referência (reference model instance)}

Utilizando-se da estrutura criada com os elementos da FIM (personagens e infraestrutura) e do modelo de referência mencionado, um script foi desenvolvido para exemplificar um desenvolvimento de produto com todas as situações envolvidas. Neste script, que contém atos e cenas como em uma peça teatral, os papéis de cada personagem já são previamente definidos. Todas as dimensões do negócio (estratégias, atividades, informação, recursos e organização) e as limitações da FIM (por exemplo, quanto a problemas de integração) são consideradas nesta instância.

Como um exemplo, parte do script que simula o desenvolvimento de uma nova linha de redutores modulares, produzido na FIM, é apresentado em seguida. Este exemplo ilustra o Conceito do Produto, que é uma das mais importantes fases. Nesta fase as principais características do produto são desenvolvidas. As especificações básicas do produto e planejamento de tempos de desenvolvimento, que foram identificadas na fase anterior de concepção, são aqui avaliadas e detalhadas. A especificação do produto, baseado em Pugh (1990), é a referência básica para todas as outras atividades de desenvolvimento. Considera diversos aspectos, tais como custos alvo, volumes de produção, desempenho do produto, ciclo de vida do produto, padronizações, restrições da empresa e requisitos do consumidor. Os conhecimentos envolvidos nesta parte relacionam-se à Engenharia Simultânea, ao PDT (Product Development
Team), ao QFD (Quality Function Deployment), à Tecnologia de Grupo, ao BOM (Bill of Material), ao PDM (Product Data Management), ao CAD (Computer Aided Design), ao CAPP (Computer Aided Process Planning), ao Target Costing, às Decisões Make-or-Buy, entre outros. Esta pequena apresentação é apenas parte de todo o script do desenvolvimento do produto.

Exemplo do Script - Conceito do Produto

“A sra. Thaís Mercado e o sr. Alceu Dispor realizam uma pesquisa de mercado para o nova família de redutores. Após as entrevistas com os clientes, os requisitos principais são selecionados e agrupados. Um relatório com os requisitos dos clientes é enviado para a sra. Isolda Qualli.

A sra. Qualli junto com os membros do PDT e fornecedores-chave inicia a aplicação da técnica de QFD. Os principais requisitos dos clientes são alta durabilidade, baixa frequiência e custo de manutenção e limpeza da área de trabalho.

Como resultado da análise de QFD eles decidem melhorar o sistema de lubrificação, aumentar a vida dos rolamentos e reduzir os custos e frequiência de manutenção. O problema com o vazamento de óleo, para manter a área de trabalho limpa, é resolvido com a diminuição da rugosidade superficial no assento dos retentores dos eixos de entrada e saída. A sra. Qualli prepara um relatório de requisitos técnicos com essas informações. 
Em seguida, o sr. Décio Dezaine especifica a família de redutores (módulo e número de dentes das engrenagens, redução, entre outros dados) e prepara os desenhos de conjunto, considerando os requisitos técnicos. O sr. Dezaine e o Sr. Sabino Sequencia consultam, então, as diretrizes do produto e preparam os desenhos dos principais itens da família de redutores. O sr. Dezaine utiliza o sistema de classificação para localizar subconjuntos e itens existentes que possam ser reutilizados. Ele verifica que alguns desenhos de eixos e engrenagens podem ser reutilizados com pequenas modificações.

Utilizando essas informações recuperadas, o sr. Sequencia cria a primeira versão da estrutura de produto. Ele elabora, então, planos de processo para os itens da estrutura de acordo com diferentes abordagens: planejamento variante para itens recuperados, planejamento automático para itens paramétricos e planejamento interativo para os demais itens. Nessa fase, são elaborados somente os planos de processo macro para serem utilizados na estimativa de custo dos itens. Os planos de processo serão detalhados na fase seguinte.

O sr. Dezaine, o sr. Sequencia e a sra. Lídia Taime iniciam a análise de "make-or-buy" para o eixo de saída. Com as informações do plano de processo macro, tais como a sequiência de operações, os tempos de fabricação e o custo do ferramental, eles calculam o custo de fabricação através do cost rollup. Eles analisam também o custo, o tempo de entrega, a qualidade, entre outras características dos fornecedores. Após esta análise eles decidem pela fabricação do eixo.

Após a análise de "make-or-buy", a sra. Lídia Taime recebe a lista de itens que serão fabricados e realiza a análise de capacidade com base na previsão de vendas. Ela verifica que não há capacidade suficiente para a retificação dos eixos. O sr. Sabino Sequencia especifica as características técnicas para uma nova retificadora. A sra. Carla Caunt planeja a compra e verifica o plano de investimentos para a retificadora.

A sra. Daliga apresenta os resultados da fase de concepção para os diretores da FIM. O relatório de concepção é aprovado e a fase de projeto é iniciada."

Apesar do texto do script, há também uma representação desta instância do modelo de referência na forma de um cartoon (Figura 3). Este tipo de representação tem sido aprovado pela maioria dos visitantes da FIM como sendo um meio mais fácil de se entender do que as representações mais técnicas do modelo de referência, tais como as resultantes das ferramentas de modelagem utilizadas.

\subsection{Estrutura organizacional (organizational change)}

Para suportar o processo de desenvolvimento de produtos, algumas posições em uma estrutura organizacional tiveram que ser criadas e um time de desenvolvimento de produtos (PDT - Product Development Team), baseado nas propostas de Clausing (1993), foi montado a partir do conjunto de personagens do script. Cargos e funções foram atribuídos aos personagens de acordo com seu papel na história e a dimensão organização especificada no modelo de referência.

\subsection{Definição das Informações (information definition)}

A definição das informações contidas no script é diretamente relacionada à definição das atividades especificadas no modelo de referência. Estas informações incluem numeração de peças, lista de materiais, desenhos, planos de processo, de controle, relatórios, listas de verificação, entre outros, e fazem parte do conteúdo dos documentos usados durante o processo de desenvolvimento de produtos. Além disso, também é necessário definir questões tais como formatos, regras de mudanças (tais como status, revisão etc.), conteúdos, entre outros aspectos.

\subsection{Implantação de sistemas (systems implantation)}

Uma infra-estrutura de hardware e software e outros dispositivos necessários, utilizados pelos personagens no script para o desenvolvimento do projeto, foram selecionadas de forma compatível com os recursos especificados no modelo de referência para o desenvolvimento de produtos (por exemplo, ferramentas para CAD, CAE e CAPP). Os fornecedores destas soluções foram selecionados, os sistemas foram implantados e então integrados. As sobreposições de sistemas, limitações e demais dificuldades relacionadas a estas soluções também foram identificadas. Em geral, buscou-se ter mais do que uma solução para cada ferramenta solicitada pelo modelo de referência. 


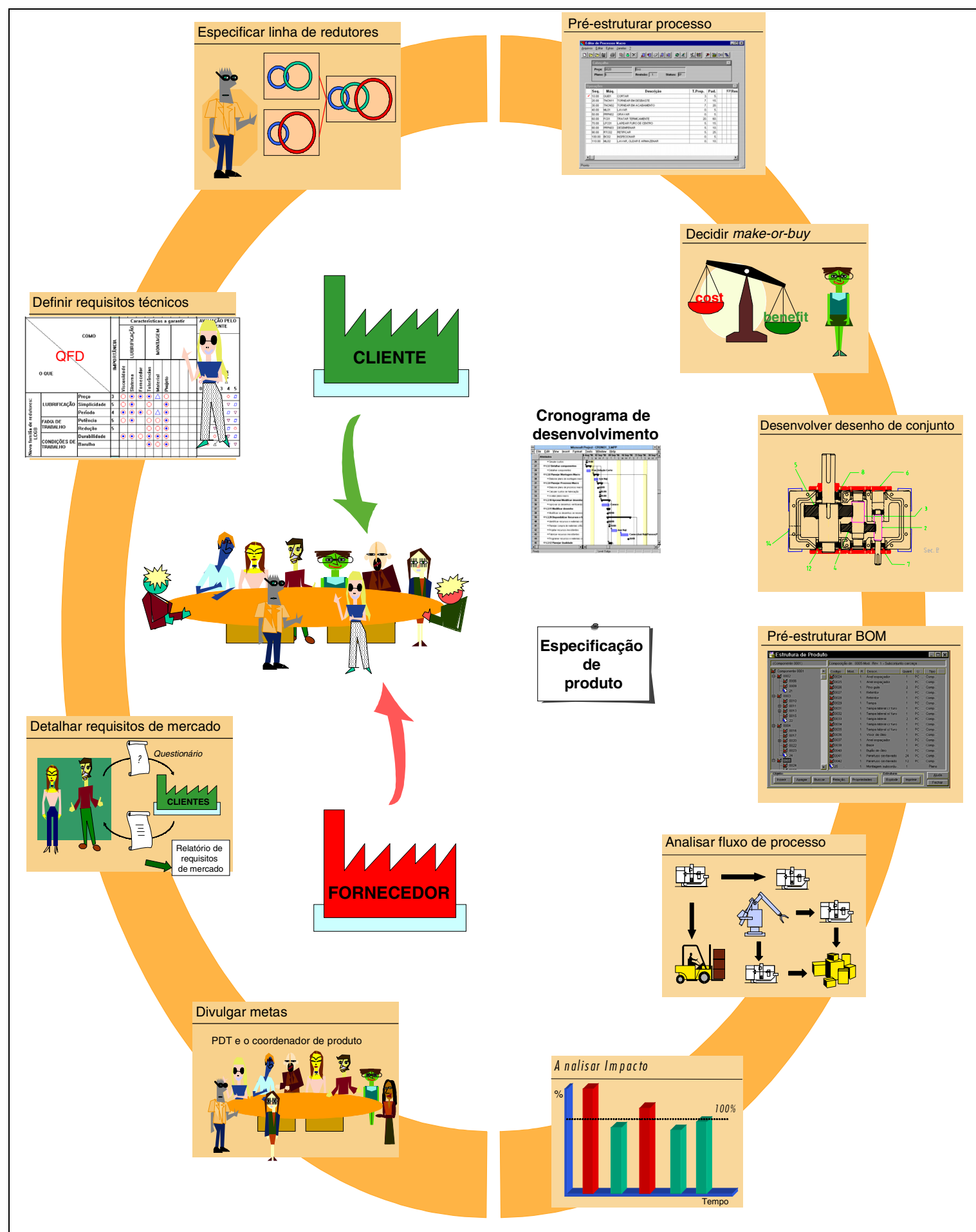

Figura 3 - Cartoon da fase de conceito

\subsection{Mapeamento do conhecimento (knowledge mapping)}

Todas as atividades anteriores são suportadas em essência pelos conhecimentos relacionados com o desenvolvimento de produtos e outras disciplinas correlatas, organizadas em uma taxonomia de conhecimentos. Esta taxonomia, além de levar em consideração a representação do desenvolvimento de produtos em um modelo de referência, baseia-se também nas principais abordagens provenientes de diferentes áreas para a análise e intervenção no processo de desenvolvimento de produto (CLAUSING, 1993; CLARK e FUJIMOTO, 1991; CLARK e WHEELWRIGHT, 1992; PUGH, 1996; PRASAD, 1996; PRASAD, 1997; entre outros), que 
por sua vez também consideram as melhores práticas das empresas de classe mundial. Esta taxonomia compõe-se de conceitos/filosofias, métodos/ técnicas, e ferramentas/sistemas que podem ser aplicados no processo de desenvolvimento de produtos.

Os conceitos/filosofias são constituídos por tipos de conhecimentos mais amplos, que servem para criar um embasamento teórico e fornecer diretrizes para a implantação dos métodos, técnicas, sistemas, ferramentas e soluções. Neste grupo podem ser relacionados, por exemplo, os seguintes conhecimentos: Business Process, Engenharia Simultânea, Lean Production, Integração de Empresas/CIM etc.

As técnicas/métodos são tipos de conhecimentos não tão abrangentes como os conceitos e filosofias e normalmente são estruturados em passos, ou relacionados com algo específico, para atingir um determinado objetivo. Muitas vezes eles relacionam-se com os conceitos e filosofias listados, podendo até ser classificados como tal. Por exemplo, DFMA (Design for Manufacturing and Assembly) pode ser classificado como um conceito. Neste grupo, os seguintes conhecimentos podem ser dados como exemplo: Análise de valores, DOE (Design of Experiments), FMEA (Failure Mode and Effect Analysis), QFD (Quality Function Deployment) etc.

As ferramentas/sistemas são tipos de conhecimentos relacionados com produtos comerciais, que podem ser utilizados no processo de desenvolvimento de produtos. Normalmente, uma ferramenta está associada a um conceito/filosofia e a uma técnica/método, sendo necessário entender estes conhecimentos prévios para utilizar adequadamente os conhecimentos de ferramentas/sistemas. Relacionados a este grupo estão, por exemplo, os seguintes conhecimentos: CAD (Computer Aided Design), CAPP (Computer Aided Process Planning), ERP (Enterprise Resource Planning) etc.

Além destes três tipos de conhecimento, pode-se adicionar à taxonomia proposta os conhecimentos específicos para produtos mecânicos, eletrônicos, mecatrônicos, ópticos etc., que dependem das particularidades de cada indústria, e os conhecimentos básicos, ligados a química, física e matemática, universais e relevantes como base para todos os outros tipos de conhecimentos.

Conforme discutido anteriormente, a forma como estes conhecimentos são usados, criados, avaliados e conduzidos em toda a organização, e no processo de desenvolvimento de produtos em particular, influencia a renovação destes conhecimentos, através das conversões existentes entre os formatos tácito e explícito possíveis de se ocorrer no ambiente.

A idéia da taxonomia apresentada aqui não significa que cada conhecimento deve ser visto de uma maneira independente. Muito pelo contrário, há múltiplas ligações (links) entre os conhecimentos destes três grupos. Uma boa forma de se visualizar esta taxonomia e navegar entre estes links é fazendo uso de um formato em hipertexto, colocado em uma base web. Pela facilidade, custo e flexibilidade de uso, isso sem comprometer o resultado final desejado, colocou-se todos os conhecimentos agrupados por esta taxonomia em páginas web na internet, denominado internamente na FIM de homepage de conhecimentos.

Os conhecimentos descritos nestas páginas web foram agrupados segundo a taxonomia proposta no formato para o trabalho com o conhecimento (conceitos/filosofia; técnicas/métodos; e ferramentas/ sistemas). Houve uma preocupação em se normalizar a forma de exposição dos conhecimentos. Isso foi obtido já que todo tipo de conhecimento relacionado foi explicado através de um texto resumido (Conceitos Básicos), com a citação das referências mais importantes (livros, artigos etc.) para que seja obtida uma compreensão mais detalhada de um conhecimento em particular, e com sites/endereços na internet e em alguns casos especialistas relacionados ao conhecimento descrito (Informações Adicionais). Buscou-se com este formato das páginas web seguir a principal recomendação de Davenport e Prusak (1998) no sentido de priorizar a indicação de onde o conhecimento está e em como obtê-lo e não em conter todo o conteúdo do conhecimento.

\subsection{Simulação e otimização do Script (simulation and script optimization)}

Seguindo-se uma filosofia de melhoramento contínuo, muitas simulações têm sido feitas para otimizar o script e melhorar a dinâmica de realização da prática do desenvolvimento de produto, preocupando-se com a integração dos sistemas computacionais envolvidos e destes com as técnicas e métodos utilizados. Algumas alternativas foram testadas para se definir quais atividades devem ser feitas em grupo ou individualmente, no computador ou manualmente etc. Esta dinâmica é mais crítica quando o ambiente é utilizado para finalidades educacionais, sendo necessário transmitir todo o conhecimento envolvido de uma forma didática.

Tendo este ambiente da FIM ficado pronto, passouse a utilizá-lo para os propósitos mencionados 
anteriormente. Na preparação de todas estas atividades na FIM, há uma grande interação desta (ligada à universidade) com diversas empresas. De forma inovadora, pesquisa, ensino e assessoria ocorrem de forma entrelaçada. Há pesquisas sendo feitas em todas estas atividades, por alunos de iniciação científica e de pós-graduação, algumas delas mantidas por recursos de empresas. Há assessoria quando realiza-se intervenções em empresas e trazse problemas e soluções, em cada uma das atividades mencionadas, para serem testadas e implementadas na FIM. Por fim, há ensino permeando todas as atividades, quando o ambiente da FIM é aberto para treinamento de pessoal do desenvolvimento de produtos da empresa, sendo esta a fase mais visível da interação FIM-Empresa, e que será mais discutido no próximo ítem.

\section{Destacando o papel do treina- mento na interação Universidade/ Empresa realizada pela FIM}

Um dos principais propósitos deste ambiente da FIM é construir um espaço educacional valioso para as pessoas aprenderem e praticarem suas habilidades relacionadas ao desenvolvimento de produtos. Nesta linha de ensino podemos classificar os seguintes tipos de atividades:

- Cursos: desenvolvidos para transmitir a visão integrada do processo de desenvolvimento de produto ou de parte dele. Neles os participantes assumem o papel de personagens da FIM e acompanham o processo de desenvolvimento de um produto desta fábrica com o apoio do script. Durante este processo os participantes tomam contato com os conceitos, teorias, soluções, ferramentas, entre outros elementos, realizando atividades do processo com diferentes graus de "vivência" ou participação. Cobrindo desde atividades onde eles assistem instrutores reproduzindo as ações dos personagens da FIM conforme descrito no script, até àquelas em que eles próprios reproduzem as ações dos personagens tomando decisões em seu lugar, ou seja, sem conhecerem o final da cena e com liberdade para tomar as decisões;

- Demonstrações: apresentações onde é permitido aos participantes, inseridos dentro do ambiente da FIM, assistir (demonstração passiva) ou participar (demonstração ativa) da aplicação de uma ou um conjunto determinado de soluções para o processo de desenvolvimento de produto (tais como técnicas, metodologias, ferramentas, sistemas, entre outras). Isto é feito situando-se o contexto da solução na história (script) de desenvolvimento;
- Workshop - Rolling Play Game: trata-se do caso extremo de "vivência" e envolvimento de ensino. Nele os participantes desenvolvem um produto totalmente novo e com potenciais reais de vir a ser produzido (o que significa inclusive alguma empresa interessada), tendo como base o modelo de referência e os recursos da FIM. Os participantes são acompanhados por instrutores e especialistas, os quais assumem o papel de presidentes e diretores da FIM, e orientam o grupo na utilização das técnicas e ferramentas específicas durante o desenvolvimento do projeto.

Em Zancul et al. (1998) e em Aguiar et al. (1997) detalha-se mais estas classificações e os resultados de suas aplicações.

Essencialmente então, ao mesmo tempo em que a história é contada, os participantes são levados a realizar diversos tipos de atividades que têm por objetivo passar os conceitos e exemplos necessários para a compreensão desta história, e também permitem que eles experimentem a sensação de "vivenciá-la", ou seja, de reproduzir as ações dos personagens ou tomar decisões em seu lugar. Descrevendo-se mais detalhadamente, tem-se então dentro destas atividades:

- Apresentações formais: trata-se de apresentações expositivas tradicionais (com slides em canhões multmídia) e que buscam transmitir conhecimentos específicos. Um exemplo é uma apresentação sobre Bill of Material (BOM) onde são definidos os principais termos, usos e tipos de estruturas de produto. O intuito nesta apresentação é dar aos participantes os elementos básicos para a compreensão da história que foi estruturada para mostrar a relação entre a BOM e diversos aspectos do processo de desenvolvimento de produto;

- Demonstrações pré-gravadas no computador: são gravações em arquivos de computador de formato multimídia “SCR",'PE” onde demonstra-se o funcionamento de um sistema (software) no decorrer da história narrada no script. Por exemplo, no script há uma fase de elaboração dos desenhos de projeto num software de CAD. Numa das atividades desta parte específica do curso, o participante que assumiu o papel deste personagem inicia no computador a demonstração prégravada mostrando passo-a-passo a elaboração deste desenho;

- Demonstrações pelos instrutores: atividade em que os instrutores assumem o papel de personagens e reproduzem a cena tal que o participante pode observá-los. Um exemplo é uma atividade sobre CAM (Manufatura Auxiliada por Compu- 
tador), onde os instrutores, assumindo personagens e conforme o script, simulam o "Caminho da Ferramenta" e geram o "Programa CN (Comando Numérico)" da máquima. Esta ação dificilmente poderia ser realizada de outra forma pois exigiria do participante um conhecimento muito específico para a sua reprodução. Nesta atividade, então, os participantes acompanham esta ação e visualizam toda atividade como expectadores num teatro;

- Simulação: atividades onde os participantes assumem papéis de personagens e reproduzem as ações no cenário conforme o seu papel descrito no script. Um exemplo é a atividade de Planejamento do Processo Macro, onde os participantes recebem um guia com instruções detalhadas e preparam os planos de processo no computador conforme estas instruções;

- Vivenciamento: mesmo que o anterior, porém, os participantes não tomam conhecimento de toda a cena e sim do contexto e início. Desta forma, eles partem de um estado e atingirão um resultado final único, não previsto pelos instrutores. Um exemplo é uma atividade de FMEA (Failure Mode and Effect Analysis) onde os participantes recebem todas as informações pertinentes a esta análise e realizam-na livremente, sem intervenções dos instrutores.

Cada cena e ato do script pode ser ilustrado empregando um diferente conjunto de atividades, cada qual de diferentes tipos. O desafio nesta combinação é conseguir manter o maior grau de vivência e participação do aluno tal a fornecer-lhe a visão integrada deste processo e a incorporação da história de desenvolvimento de produto contada. Tudo isto guiando-se pelas restrições de tempo e público-alvo.

A primeira aplicação em forma de curso é detalhadamente apresentada em Zancul et al. (1998), Rozenfeld et al. (1998). Ela foi estruturada num curso de 40 horas e restrita ao máximo de 6 alunos. Tal carga foi dividida em 10 módulos de quatro horas durante o período de uma semana. Neste intervalo de tempo os participantes acompanhavam o script, narrado por um instrutor, e realizavam atividades dos tipos de vivenciamento e simulação, intercaladas com apresentações de conceitos, técnicas e sistemas sempre que tais conhecimentos fossem pré-requisitos para o acompanhamento das demais. A aplicação desenvolvida continha quatro (4) atividades do tipo Vivenciamento, nove (9) de Simulação e vinte e oito (28) do tipo Apresentação. Todas as atividades do curso foram também preparadas para serem realizadas entre a mesa de reunião e computadores do "escritório" da FIM e o "chão-de-fábrica".
Esta aplicação, ou seja o curso com este formato, foi aplicado três vezes com alterações superficiais entre elas: a primeira para alunos de graduação no quinto ano de engenharia e duas para profissionais de empresa na área de engenharia (contendo responsáveis por este processo, projetistas, processistas e consultores). Os resultados destas primeiras análises, conforme Zancul et al. (1998), evidenciam que o curso tem atingido os objetivos propostos de integração, maior eficiência de ensino e uma experiência de projeto mais próxima do real.

Estas primeiras análises deixaram evidentes também a existência de duas importantes restrições: o tempo longo do curso e o número de participantes reduzido (ZANCUL et al., 1998; ROZENFELD et al., 1998). O tempo de uma semana, embora suficiente para alunos de graduação, dificulta a participação de profissionais de empresa que têm dificuldade de se ausentar por tão longo tempo de suas funções. Considerando também que tentativas de aplicação do curso com espaços de tempo entre os módulos maior que um dia mostraram-se fortemente prejudiciais à compreensão da história e à transmissão do caráter de integração (ZANCUL et al., 1998), inviabilizando portanto a alternativa de decompô-lo e aplicá-lo intermitentemente. Já a limitação de 6 alunos por turma mostrou-se ainda mais preocupante, pois inviabiliza o curso quando comparado aos recursos necessários. Isto porquê, além da estrutura física, o curso assim elaborado exigia no mínimo 4 instrutores que acompanhavam os participantes durante todo o tempo e que os auxiliavam durante as atividades. Mantendo-se esta relação de participantes por recursos, nos cursos derivados desta abordagem, seria inviável seu uso intensivo e disseminação como alternativa ao ensino tradicional. Procurou-se, então, desenvolver uma nova aplicação que fosse capaz de atingir os objetivos iniciais propostos, mantivesse os acertos e virtudes da aplicação aqui descrita, com uma menor carga horária e estendendo o número máximo de participantes.

Manteve-se as principais características da abordagem de ensino por meio de um cenário de engenharia simultânea. Foi também baseada em um script, no Modelo de Referência para o Processo de Desenvolvimento de Produto da FIM e nos elementos do cenário (recursos, informação, modelos de referência, script, organograma, entre outros).

O objetivo principal era obter um curso aplicável, com pequenas variações, dentro de um tempo total de 16 horas composto por 4 módulos de 4 horas. O script, modelo de referência e demais elementos se mantiveram os mesmos das aplicações anteriores, relevados pequenos aprimoramentos. 
Já o espaço físico, forma de condução do curso e de narração do script eram diferentes em relação à aplicação anterior. Em lugar das dependências da FIM o curso foi realizado em um auditório, previamente preparado, capaz de comportar 30 pessoas. Foi instalado um grande painel de aproximadamente 3 metros de comprimento por $1,5 \mathrm{~m}$ de altura ilustrando com figuras em quadrinhos a história descrita no script, o mesmo que, dentro da FIM, apoiou a aplicação do curso anterior. Também foram implantados dois computadores ligados em rede, cada qual conectado a um canhão multimídia. Uma câmera de vídeo com tripé conectada a um dos canhões citados e um sistema de som serviam de apoio aos instrutores.

No primeiro módulo foram realizadas apresentações dos conceitos que fundamentam o cenário que são: visão holística, integração de empresas, processos de negócio e modelagem de empresa. Em seguida, deu-se início à condução da história. Cada participante recebeu um crachá contendo a foto e o nome de um dos personagens da FIM. O instrutor pôs-se a narrar a história apontando para as figuras correspondentes à cena narrada no painel do centro da sala. Ao mesmo tempo, um instrutor filmava a parte indicada do painel mostrando a figura em seus detalhes no telão. Enquanto isto, os participantes podiam acompanhar no telão pelas figuras e pelo próprio script cuja cópia constava entre o material didático recebido. Em seguida à apresentação da cena transcorriam-se as atividades que podiam ser de diferentes tipos conforme explicado anteriormente. Nas atividades do tipo Apresentação o instrutor realizava a apresentação com apoio de slides, os quais, como as atividades do tipo Demonstração Pré-Gravada no Computador, eram apresentados no telão. Já as atividades do tipo Demonstração eram realizadas na frente do auditório onde os instrutores, com crachás referentes aos personagens citados na cena, reproduziam as ações descritas no script. Quando eram empregados recursos de informática nestas atividades os alunos podiam acompanhar as ações pelos telões. Concebeu-se dois "telões" e dois computadores para transmitir a idéia de paralelismo. Assim, houve momentos em que ações distintas, complementares e integradas pelas ferramentas de software (os micros em rede permitiam compartilhamento de informação) eram realizadas nos dois micros e acompanhadas concomitantemente pelos participantes do curso. Por fim, nas atividades de Simulação os participantes eram chamados à frente do auditório e, apoiados pelos instrutores, reproduziam a ação descrita no script.

Cada uma destas atividades foi exclusivamente preparada para esta nova aplicação. Incluiu-se atividades dos tipos: apresentações formais (num total de 19 apresentações com uma duração média de 20 minutos sendo a menor de 5 e a máxima de 40); demonstrações pré-gravadas no computador (num total de 6); demonstrações (num total de 7) e simulações (num total de 4).
Vê-se, portanto, que o conteúdo de didática ativa diminuiu em relação à aplicação anterior. Atividades do tipo "vivência", com maior liberdade para os participantes tomarem as ações, foram suprimidas e houve um menor número de simulações que passou de 9 para 4 na aplicação atual. Porém, a carga horária foi reduzida em cerca de $60 \%$ (de 40 para 16 horas), com a possibilidade de um número de participantes mais próximo aos níveis alcançados pelo ensino tradicional.

\subsection{Uma análise dos resultados obtidos neste ambiente educacional do ponto de vista do trabalho com os conhecimentos envolvidos}

Certamente, construiu-se um interessante meio para as pessoas compreenderem e aprenderem a complexidade envolvida em um processo de desenvolvimento de produtos. Encontram-se presentes na realização destas simulações as três características-chave da criação do conhecimento defendidas por Nonaka \& Takeuchi (1995):

- há o uso da linguagem figurada, implícita na metáfora e analogia representada pelo uso da dramatização (script) para representar o desenvolvimento de produtos, onde um cenário foi criado para tentar transmitir as experiências e habilidades pessoais (conhecimentos) de um personagem para o outro;

- o conhecimento pessoal deve ser compartilhado, o que ocorre quando as pessoas assumem diferentes personagens (diferentes visões) durante a execução da dramatização e, induzidos pelo script, interagem com os outros personagens (membros) do time propondo soluções para os problemas relacionados ao desenvolvimento de produtos;

- finalmente, a ambigüidade e a redundância criam novos conhecimentos, como uma fonte de novas idéias e de novas perspectivas de análise de problemas, o que é percebido nas diferentes formas com que os métodos, técnicas e ferramentas são apresentados na dramatização, através de apresentações, leitura, prática e discussão, e pela navegação na homepage de conhecimentos envolvidos no processo de desenvolvimento de produtos.

Seguindo ainda a abordagem de Nonaka e Takeuchi (1995), considerando agora os quatro modos que compõem a espiral de conversão do conhecimento entre o formato tácito e explícito, percebe-se que os modos de socialização e externalização são mais estimulados pelo ambiente físico de simulação via dramatização do desenvolvimento de produtos, devido ao inerente trabalho com o conhecimento 
tácito nesta atividade, enquanto que a combinação e a internalização são mais estimuladas pelo manuseio dos conhecimentos mapeados e disponíveis na homepage de conhecimentos, inerentemente ligada ao conhecimento explícito. Fica evidente a adequada complementação destes dois recursos, a homepage de conhecimentos e a dramatização, no sentido de estimular a criação de conhecimentos.

Analisando este ambiente de prática da dramatização do desenvolvimento de produtos e a homepage de conhecimentos sob o prisma das quatro atividades inter-relacionadas descritas anteriormente, ligadas à obtenção de competências/ capacidades conforme proposta de Leonard (1995), o ambiente físico focaliza mais o aumento da solução compartilhada de problemas, devido à abrasão criativa (creative abrasion) ser estimulada pela dramatização onde pessoas assumem diferentes personagens e precisam defender diferentes pontos de vista em conflitos de grupos. Devido a uma característica inerentemente ligada a qualquer simulação, um clima que encoraja a experimentação também é incrementado, e a necessidade de uso e integração de soluções comerciais é uma oportunidade para implementar e integrar novos processos técnicos e ferramentas. Por outro lado, a homepage de conhecimentos é um meio inicial para compreender alguns tipos de conhecimentos tecnológicos importados e absorvidos de fora da empresa e aprender com o mercado, embora outros recursos adicionais sejam necessários para se fazer isso.

Uma importante implicação gerencial desta pesquisa, além da utilização do modelo de referência como um mapa para a localização e visualização da interrelação entre os conhecimentos envolvidos no processo de desenvolvimento de produtos, é de que os conhecimentos tanto no formato tácito como explícito são importantes para melhorar o desempenho de um time multifuncional de desenvolvimento de produtos, mais considerações a este respeito podem ser obtidos em Silva e Rozenfeld (1998).

\section{Considerações finais}

Diversos resultados têm sido obtidos das aplicações discutidas anteriormente e do desenvolvimento do ambiente da FIM, sendo resumidamente colocadas abaixo:

- um modelo de referência completo e que pode ser customizado para cada situação específica;

- uma infraestrutura, principalmente em termos de software e hardware, para suportar as práticas da engenharia simultânea;
- validação de diversas soluções comerciais e de pesquisas;

- um local para qualificar pessoas para o processo de desenvolvimento de produtos;

- um script descrevendo as principais situações e problemas que podem ocorrer durante o processo de desenvolvimento de produtos;

- um forum para discussões sobre as práticas da engenharia simultânea e o processo de desenvolvimento de produtos.

O ambiente de engenharia simultânea da FIM é resultado de anos de estudos sobre o processo de desenvolvimento de produtos e da descoberta das dificuldades envolvidas na consideração de todas as dimensões deste processo de negócios. Os resultados descritos anteriormente têm validado este ambiente já que os objetivos inicialmente propostos, de criar uma plataforma para testes de novas soluções em engenharia simultânea e de ensinar os conhecimentos envolvidos para as pessoas, têm sido atingidos e reconhecidos pelo meio empresarial (COSTA, 1997; COSTA, 1998).

O modelo de referência desenvolvido pela FIM para o desenvolvimento de produtos já tem sido aplicado em algumas empresas, como uma base para que estas customizem seus próprios modelos de referência para seu processo de negócios de desenvolvimento de produtos. O ambiente da FIM também tem sido usado para desenvolver metodologias para a implementação, integração de sistemas e conhecimentos, construção de soluções pilotos, para testar soluções comerciais, e para ajudar empresas que tenham dificuldades em áreas relacionadas etc., em bastante proximidade com as empresas inovadoras.

Como um recurso de ensino, tem ajudado especialistas de empresas a perceber o desenvolvimento de produtos em seu todo, como um processo, e de perceber a importância da filosofia da engenharia simultânea e suas ferramentas para estimular o trabalho em um time multifuncional. Por fim, as experiências advindas das várias práticas realizadas neste ambiente de engenharia simultânea têm sido usadas como referência para atualizar algumas disciplinas nos cursos de graduação e de pósgraduação em engenharia das universidades participantes da FIM.

As pesquisas em andamento no momento, relacionadas com a FIM, pretendem: aprimorar as aplicações deste ambiente de engenharia simultânea com relação 
ao aspecto tempo, mantendo-se seu aspecto inovador em termos de vivência; aprimorar a forma de avaliação dos participantes das práticas do desenvolvimento de produtos, pela aplicação da tecnologia de multimídia; testar e integrar a este ambiente novas soluções e técnicas (por exemplo, a parte de engenharia de sistemas ERP); aplicar este mesmo modelo para empresas do setor eletro-eletrônico, estudando suas particularidades; aprofundar o entendimento das relações entre a taxonomia de conhecimentos e as diferentes formas de se manusear estes em seus formatos tácitos e explícitos.

Alguns desafios devem ser buscados na interação Universidade-Empresa, conforme apontado por alguns autores (FERRO, 1994; TARALLI, 1995; PLONSKI, 1995), e a experiência da FIM tem caminhado neste sentido: o da criação de uma linguagem comum entre estas duas entidades, a questão da sintonia entre o tempo adequado pela empresa e pela universidade, a necessidade da publicação de artigos científicos pela universidade versus o interesse da empresa por ações imediatas como cursos e assessorias; o problema dos estilos de gerência diferente entre a universidade e a empresa; o aprendizado obtido pela universidade resultado deste processo bidirecional de cooperação com o setor produtivo.

Segundo Mindlin (1991), a universidade deve ser um centro de reflexão e formação de espírito crítico para contribuir na transformação social, cabendo reconhecer também que a universidade e a empresa podem lucrar com uma relação mais estreita, apesar das diferentes orientações que devem, aliás, ser preservadas. Este tem sido o foco da FIM em seu trabalho de interação Universidade-Empresa.

\section{Referências}

ABECKER, A.; BERNARDI, A.; HINKELMANN, K.; KÜHN, O.; SINTEK, M. Towards a technology for organizational memories. IEEE Intelligent Systems, p.40-48, May-June, 1998.

AGUIAR, A.F.S; ROZENFELD, H.; ZANCUL,E.S. Capacitação de Pessoal para o processo de Desenvolvimento de Produtos. In: XIV CONGRESSO BRASILEIRO DEENGENHARIA MECÂNICA. Anais, Bauru, 1997.

BIRCHALL, D.; SMITH, M. Developing the skills of technologists in strategic decision making - a multimedia case approach. International Journal of Technology Management, v.15, n.8, p. 854-868, 1998.
BREMER, C.F. The FIM - Integrated Model Factory and its application on generating and transference of knowledge for world class industries. In: $6^{\text {th }}$ WORLD CONFERENCEONCONTINUINGENGINEERING EDUCATION, Proceedings, São Paulo, 1995.

CLARK, K.; FUJIMOTO, T. Product development performance: strategy, organization and management in the world auto industry. Boston: Harvard Business School Press, 1991. 409p.

CLARK, K.; WHEELWRIGHT, S.C.

Revolutionizing product development: quantum leaps in speed, efficiency, and quality. New York: The Free Press, 1992. 363p.

CLAUSING, D. Total quality development: a step-bystep guide to world-class concurrent engineering. New York: ASME Press, 1993. 505p.

COSTA, E.A. Entra em operação a fábrica do futuro. Gazeta Mercantil, São Paulo, 31 out. 1997, p. A-9.

COSTA, E.A. Universidade amplia acesso a informação. Gazeta Mercantil, São Paulo, $1^{\circ}$ mar. 1998, p. A-12.

CUSUMANO, M.; NOBEOKA, K., Thinking beyond lean: how multi-project management is transforming product development at Toyota and other companies. New York: Simon \& Schuster, 1998. 327p.

DAVENPORT, T.; PRUSAK, L. Working Knowledge. Boston: Harvard Business School Press, 1998. 199p.

FERRO, J.R. Modelos Gerenciais de Pesquisa e Desenvolvimento. In: Universidade e Indústria - Depoimentos, p.15-25, São Carlos: EDUFSCar, 1994, 70p.

GARVIN, D. Levering process for strategic advantage. Harvard Business Review, v.73, n.5, p.76-90, 1995.

HEIJST, G.; SPEK, R.; KRUIZINGA, E. Corporate memories as a tool for knowledge management. Expert Systems with Applications, p.41-54, July, 1997.

JUNNARKAR, B. Leveraging collective intellect by building organizational capabilities. Expert Systems with Applications, p.29-40, July, 1997.

LEONARD, D. Wellspring of Knowledge. Boston: Harvard Business School Press, 1995. 334p.

MAURER, H. Web based knowledge management. Computer, p.122-123, March, 1998. 
MINDLIN, J. Universidade, tecnologia e empresa.

Educação Brasileira, v.13, p.151-158, 2.semestre, 1991.

NICOLETTI, S. A concurrent engineering decision model: management of the project activities information flows. International Journal of Production Economics, p.115-127, January, 1998.

NONAKA, I.; TAKEUCHI, H. The Knowledge Creating Company. Oxford University Press, 1995.351p.

PLONSKI, G.A. Cooperação Empresa-Universidade: antigos dilemas, novos desafios. Revista USP, n.25, p.32-41, março/maio, 1995.

PRASAD, B. Concurrent engineering fundamentals: integrated product and process organization, V.I, New Jersey: Prentice Hall International Series, 1996. 478p.

PRASAD, B. Concurrent engineering fundamentals: integrated product and process organization, V.II, New Jersey: Prentice Hall International Series, 1997. 490p.

PROKESCH, S. Unleashing the power of learning: an interview with British petroleum's John Browne. Harvard Business Review, p.147-168, SeptemberOctober, 1997.

PUGH, S. Total design: methods for successful product engineering. Great Britain: AddisonWesley, 1990.398p.

PUGH, S. Creating innovative products using total design: the living legacy of Stuart Pugh. Massachusetts: Addison-Wesley, 1996. 533p.
ROZENFELD, H. Reflexões sobre a Manufatura Integrada por Computador (CIM). In: MANUFATURA CLASSE MUNDIAL: MITOS E REALIDADE, Anais, São Paulo, 1996.

ROZENFELD, H.; AGUIAR, A.S.; OLIVEIRA, C.B.M.; OMOKAWA, R. Development of a Concurrent Enginering Scenario for Educational Purposes. In: $2^{\text {nd }}$ INTERNATIONAL CONFERENCE ON EDUCATION AND MANUFACTURING. Proceedings, San Diego, CA, 1998.

SCOTT, J.E. Organizational knowledge and the Intranet. Decision Support Systems, p.3-17, May, 1998.

SILVA, S.L., ROZENFELD, H. Uma Proposta de Gestão do Conhecimento no Desenvolvimento de Novos Produtos. In: BUSINESS IN THE KNOWLEDGE ERA. Anais, CRIE/COPPE/UFRJ, Rio de Janeiro, 1998.

TARALLI, C. Universidade - Indústria: Parceiras na Inovação. Revista USP, n.25, p.42-47, março / maio, 1995.

TEECE, D.J. Capturing value from knowledge assets. California Management Review, v.40, n.3, p.55-79. 1998.

ZANCUL, E.; AMARAL, D.C.; ROZENFELD, H. Implantação de um ambiente modelo para o desenvolvimento de produtos. In: XVIII ENCONTRO NACIONAL DE ENGENHARIA DE PRODUÇÃO. Anais, Niterói, 1998.

submetido em maio/2003

Aprovado em setetembro/2004

Agradecimentos: a todos os pesquisadores do Grupo de Engenharia Integrada (EI) e as empresas e entidades governamentais de fomento que participam dos projetos deste grupo. 